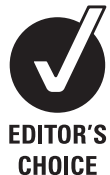

${ }^{1}$ Critical Care Research Unit, Southampton University Hospital, Southampton, UK ${ }^{2}$ Division of Developmental Origins of Health and Disease, School of Medicine, University of Southampton, Southampton University Hospitals,

Southampton, UK

${ }^{3}$ Division of Infection, Inflammation and Immunity, School of Medicine, University of Southampton, Southampton University Hospital,

Southampton, UK

\section{Correspondence to}

Dr A Dushianthan, CE 93, MP 24, E-Level, Centre Block, Southampton University Hospital, NHS Trust, Tremona Road, Southampton S016 6YD, UK; dushianthan@tiscali.co.uk

Received 26 January 2011 Accepted 5 May 2011 Published Online First 4 June 2011

\title{
Acute respiratory distress syndrome and acute lung injury
}

\author{
A Dushianthan, ${ }^{1}$ M P W Grocott, ${ }^{1,2}$ A D Postle, ${ }^{3}$ R Cusack ${ }^{1}$
}

\section{ABSTRACT}

Acute respiratory distress syndrome (ARDS) is a life threatening respiratory failure due to lung injury from a variety of precipitants. Pathologically ARDS is characterised by diffuse alveolar damage, alveolar capillary leakage, and protein rich pulmonary oedema leading to the clinical manifestation of poor lung compliance, severe hypoxaemia, and bilateral infiltrates on chest radiograph. Several aetiological factors associated with the development of ARDS are identified with sepsis, pneumonia, and trauma with multiple transfusions accounting for most cases. Despite the absence of a robust diagnostic definition, extensive epidemiological investigations suggest ARDS remains a significant health burden with substantial morbidity and mortality. Improvements in outcome following ARDS over the past decade are in part due to improved strategies of mechanical ventilation and advanced support of other failing organs. Optimal treatment involves judicious fluid management, protective lung ventilation with low tidal volumes and moderate positive end expiratory pressure, multi-organ support, and treatment where possible of the underlying cause. Moreover, advances in general supportive measures such as appropriate antimicrobial therapy, early enteral nutrition, prophylaxis against venous thromboembolism and gastrointestinal ulceration are likely contributory reasons for the improved outcomes. Although therapies such as corticosteroids, nitric oxide, prostacyclins, exogenous surfactants, ketoconazole and antioxidants have shown promising clinical effects in animal models, these have failed to translate positively in human studies. Most recently, clinical trials with $\beta 2$ agonists aiding alveolar fluid clearance and immunonutrition with omega-3 fatty acids have also provided disappointing results. Despite these negative studies, mortality seems to be in decline due to advances in overall patient care. Future directions of research are likely to concentrate on identifying potential biomarkers or genetic markers to facilitate diagnosis, with phenotyping of patients to predict outcome and treatment response. Pharmacotherapies remain experimental and recent advances in the modulation of inflammation and novel cellular based therapies, such as mesenchymal stem cells, may reduce lung injury and facilitate repair.

\section{INTRODUCTION}

Acute respiratory distress syndrome (ARDS), and its milder form acute lung injury (ALI), are a spectrum of lung diseases characterised by a severe inflammatory process causing diffuse alveolar damage and resulting in a variable degree of ventilation perfusion mismatch, severe hypoxaemia, and poor lung compliance. ${ }^{1}$ Patients with ARDS are often mechanically ventilated during the course of their illness. Morbidity and mortality remains high and early recognition of patients is a vital step in providing appropriate care. Due to the broad range of precipitating conditions, patients can present to any medical or surgical specialty with acute respiratory deterioration. Prompt appropriate management with intensive care unit (ICU) provision is essential to improve outcome. The objectives of this review are to provide a clinical approach to the diagnosis and management of ARDS, clarify current definitions and their shortcomings, and evaluate the clinical evidence for established and proposed treatment strategies.

\section{DEFINITION}

ARDS was first reported by Ashbaugh et al in $1967 .{ }^{2}$ They described a rapid onset of tachypnoea and hypoxaemia, with loss of lung compliance and bilateral infiltrates on chest radiograph, in otherwise healthy young individuals. Although the ARDS precipitating illnesses differed between patients, they had similar clinical and pathological features. ${ }^{2}$ Differentiating pulmonary oedema secondary to heart failure from ARDS was difficult, and in the subsequent decades, the pulmonary artery catheter was widely used to measure pulmonary artery wedge pressure to facilitate diagnosis and management. Furthermore, the advent of the specialty of intensive care medicine resulted in improved survival and enabled greater understanding of ARDS. However, much of this early work is difficult to interpret due to the lack of a consistent definition of ARDS.

The American-European Consensus Conference (AECC) proposed a definition, which is now widely accepted as a simple diagnostic tool for patient characterisation and research trial conduct. There are three diagnostic criteria for ARDS: the presence of acute severe hypoxaemia (defined as a ratio of arterial oxygen tension over fractional inspired oxygen $\left(\mathrm{PaO}_{2} / \mathrm{FiO}_{2}\right)<200 \mathrm{~mm} \mathrm{Hg}(26.7 \mathrm{kpa})$ ), bilateral infiltrates on chest radiography (CXR), and the absence of raised pulmonary artery wedge pressure (table 1). ${ }^{3}$ If the $\mathrm{PaO}_{2} / \mathrm{FiO}_{2}$ is $>200 \mathrm{~mm} \mathrm{Hg}$ $(26.7 \mathrm{kPa})$ and $<300 \mathrm{~mm} \mathrm{Hg}(40 \mathrm{kPa})$, the criteria for ALI are met.

AECC diagnostic criteria are a relatively crude screening tool for identifying patients with ARDS, and are recognised to have limitations relating to specificity and reproduciblity. ${ }^{6}$ The degree of acuteness is not defined by the AECC criteria; however, $<72 \mathrm{~h}$ from the onset of the precipitating cause is used by many as an arbitrary diagnostic time frame. Furthermore, the degree of hypoxaemia can vary depending on the amount of positive end 
Table 1 Diagnostic criteria for ARDS

\begin{tabular}{|c|c|c|c|}
\hline Defining components & AECC criteria $^{3}$ & Murray's Lung Injury score* ${ }^{*}$ (LIS) ${ }^{4}$ & Delphi consensus $^{5}$ \\
\hline 1) Onset & Acute onset & Not defined & Rapid onset $<72 \mathrm{~h}$ \\
\hline 2) Chest radiography & $\begin{array}{l}\text { Bilateral infiltrates seen on } \\
\text { frontal chest radiograph }\end{array}$ & $\begin{array}{l}\text { Alveolar consolidation } \\
\text { No consolidation, score } 0 \\
1 \text { quadrant, score } 1 \\
2 \text { quadrant, score } 2 \\
3 \text { quadrant, score } 3 \\
4 \text { quadrant, score } 4\end{array}$ & $\begin{array}{l}\text { Bilateral airspace disease involving } \geq 2 \text { quadrants on } \\
\text { frontal chest radiograph } \dagger\end{array}$ \\
\hline 3) Hypoxaemia (mm Hg) & $\mathrm{PaO}_{2} / \mathrm{FiO}_{2} \leq 200$ & $\begin{array}{l}\mathrm{PaO}_{2} / \mathrm{Fio}_{2} \geq 300 \text { Score } 0 \\
\mathrm{PaO}_{2} / \mathrm{Fi}_{2} 225-299 \text { Score } 1 \\
\mathrm{PaO}_{2} / \mathrm{Fi}_{2} 175-224 \text { Score } 2 \\
\mathrm{PaO}_{2} / \mathrm{Fi}_{2} 100-174 \text { Score } 3 \\
\mathrm{PaO}_{2} / \mathrm{Fi}_{2}<100 \text { Score } 4\end{array}$ & $\mathrm{PaO}_{2} / \mathrm{FiO}_{2}<200$ \\
\hline $\begin{array}{l}\text { 4) Exclusion of hydrostatic } \\
\text { pulmonary oedema }\end{array}$ & $\begin{array}{l}\text { Pulmonary artery wedge pressure } \\
\text { of } \leq 18 \mathrm{~mm} \mathrm{Hg} \text { or no clinical evidence } \\
\text { of left atrial hypertension }\end{array}$ & Not defined & No clinical evidence of congestive cardiac failure \\
\hline 5) Compliance & Not defined & $\begin{array}{l}\geq 80 \mathrm{ml} / \mathrm{cm} \mathrm{H}_{2} \mathrm{O}, \text { score } 0 \\
\geq 60-79 \mathrm{ml} / \mathrm{cm} \mathrm{H}_{2} \mathrm{O} \text {, score } 1 \\
\geq 40-59 \mathrm{ml} / \mathrm{cm} \mathrm{H}_{2} 0 \text {, score } 2 \\
\geq 20-39 \mathrm{ml} / \mathrm{cm} \mathrm{H}_{2} 0 \text {, score } 3 \\
\leq 19 \mathrm{ml} / \mathrm{cm} \mathrm{H}_{2} 0, \text { score } 4\end{array}$ & Static inspiratory system compliance $<50 \mathrm{ml} / \mathrm{cm} \mathrm{H}_{2} \mathrm{O}$ \\
\hline 6) PEEP & Not defined & $\begin{array}{l}\geq 5, \text { score } 0 \\
6-8, \text { score } 1 \\
9-11, \text { score } 2 \\
12-14, \text { score } 3 \\
\geq 15, \text { score } 4\end{array}$ & $>10$ \\
\hline 7) Predisposition & Not defined & Not defined & Direct or indirect factor associated with lung injury $\neq$ \\
\hline
\end{tabular}

*For LIS divide the aggregate sum by the number of components that were used: no lung injury, score 0 ; mild to moderate, score $0.1-2.5$; severe lung injury, score $>2.5$.

†Airspace disease is defined as the presence of one or more of the following: (1) air bronchograms, (2) acinar shadows (nodular opacities 4-10 mm in diameter with poor margination), (3) coalescence of acinar shadows, (4) silhouette sign (loss of definition of the heart border or hemidiaphragm-excluding that caused by lobar collapse.

‡Clinical syndromes associated with ARDS: (1) Direct lung injury: pneumonia, aspiration of gastric contents, fat emboli, near drowning, inhalational injury, reperfusion pulmonary oedema after transplantation, or pulmonary embolectomy; (2) Indirect lung injury: sepsis, severe trauma with shock and multiple transfusions, cardiopulmonary bypass, transfusions of blood products, and severe burns.

AECC, American-European Consensus Conference; ARDS, acute respiratory distress syndrome; $\mathrm{PaO}_{2} / \mathrm{Fio}_{2}$, ratio of arterial oxygen tension over fractional inspired oxygen; PEEP, positive end expiratory pressure.

expiratory pressure (PEEP) applied, which can either include or exclude the diagnosis in individual patients. ${ }^{7} 8$ Radiographic interpretation of ARDS criteria also lacks sensitivity and specificity, with large inter-observer variability among critical care physicians. ${ }^{9}{ }^{10}$ Pulmonary artery catheterisation for ARDS is now rarely performed in the UK and exclusion of cardiogenic pulmonary oedema clinically can be difficult as both conditions may co-exist. The correct diagnosis hinges on evaluating patients in all three aspects of the diagnostic criteria, but even with these deficiencies, the criteria have nevertheless helped to identify a cohort of patients with ARDS and allowed focused research trials since 1994. Despite the advantages of this simple definition, caution needs to applied in grouping patients with varying underlying aetiology, and hence disease progression. Invariably, a heterogeneous group of conditions are clustered together in clinical trials and this may partly explain the reason for many negative results. Rigorous assessment and management of the underlying clinical condition is an essential component of the management approach of patients with ARDS.

Other notable diagnostic criteria for ARDS are Murray's Lung Injury Score (LIS) and the Delphi consensus criteria. In 1988 Murray et al proposed a scoring system with three physiological variables: hypoxaemia, lung compliance and applied PEEP; and a fourth radiological variable: the extent of alveolar consolidation (table 1). Although used widely as an adjunct to the AECC definition in many clinical trials, LIS is now generally superseded by the AECC criteria. The limitations of the AECC definition led to the Delphi consensus exercise in 2005, by Ferguson et al. This incorporates additional variables such as compliance, and precise criteria for acute onset and predisposing factors (table 1). ${ }^{5}$ When all three diagnostic methods were evaluated against a study with postmortem findings, Delphi consensus criteria and LIS had better specificity but sensitivity was higher with AECC criteria, although the differences were not statistically significant. ${ }^{11}$

\section{EPIDEMIOLOGY \\ Incidence}

The estimated incidence of ARDS and ALI varies due to the limitations of the diagnostic criteria which result in heterogeneous populations being identified. A study of critical care units in the USA in 2005 estimated the incidence of ARDS to be 58/100 000 person years with 141500 new cases per year and an annual death rate of 59000 per year. ${ }^{12}$ European estimates are more conservative, ranging between 4.2 and 13.5/100 000 person years. ${ }^{13} 14$ In the UK there are no prospective population based studies. The Intensive Care National Audit and Research Centre (ICNARC) database, which produces a case mix report of patients admitted to ICUs, does not record data that would be required to accurately identify patients with ARDS. In Scotland in 2003, an audit study reported the incidence of ARDS to be $16 / 100000$ per year. $^{15}$

\section{Mortality}

Reported mortality rates vary widely. A pooled mortality estimate from a recent systematic review suggests that the mortality for ARDS is between 36-44\%, with little change over the two decades up to $2006 .{ }^{16}$ In contrast to this, the ARDS Network clinical trials conducted over the last two decades show a clear decline in mortality among their study populations between 1997 and 2009 (figure 1) ${ }^{22}$ although the potential for selection bias needs to be considered when interpreting mortality data from clinical trials as opposed to observational studies. The reasons for the reported decline in mortality are not clear. Several factors may have contributed, including the introduction of permissive hypercapnia and protective lung 


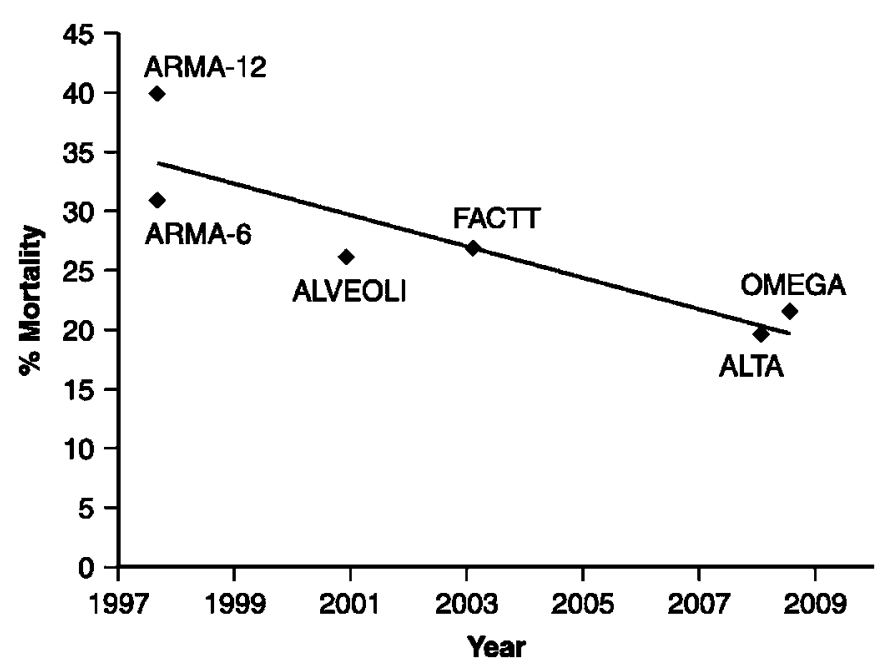

Figure 1 Observed 60 day mortality from ARDS Network clinical Trials from 1997 to 2009. ARMA, Acute Respiratory Distress Syndrome Management with Lower versus Higher Tidal Volume (ARMA-6 patients received Vt of $6 \mathrm{ml} / \mathrm{kg}$ ) (ARMA-12 patients received Vt of $12 \mathrm{ml} / \mathrm{kg})^{17}$; ALVEOLI, Assessment of Low tidal Volume and Elevated End-expiratory Volume to Obviate Lung Injury ${ }^{18}$; FACTT, Fluid and Catheter Treatment Trial $^{19}$; ALTA, Albuterol for the Treatment of ALI ${ }^{20}$; OMEGA, Omega-3 Fatty acid, Gamma-Linolenic Acid, and Antioxidant Supplementation in the Management of ALI or ARDS. ${ }^{21}$ Adapted with permission from Spragg et al. ${ }^{22}$

ventilation as well as improved supportive measures such as early antibiotics, ulcer and thrombosis prophylaxis, better fluid management, and improved nutritional and other organ support. $^{23}$

Patients with ARDS frequently have multi-organ failure, and the majority of patients die from sepsis syndrome with multiorgan failure rather than intractable respiratory failure. In a study analysing the causes of death in ARDS patients, only $16 \%$ of deaths were attributed to respiratory failure. Most of the deaths in the first 3 days were due to the underlying illness, and when they occurred later they were most frequently due to sepsis syndrome. ${ }^{24}$

\section{Aetiology and risk factors}

ARDS has many causes. Sepsis from both pulmonary and nonpulmonary origin accounts for the majority of cases. ${ }^{12}$ Common aetiological insults are documented in table 2. Mortality varies according to the aetiology, with trauma patients fairing better than patients with sepsis. ${ }^{12}$ Genetic predisposition may influence clinical outcome and many candidate genes have been identified. ${ }^{25}$ Chronic alcohol abuse, ${ }^{26} 27$ age, chronic liver disease,

Table 2 Clinical conditions associated with aetiology of ARDS (adapted from Ware and Matthay 2000 with permission) ${ }^{1}$

\begin{tabular}{ll}
\hline Direct lung injury & Indirect lung injury \\
\hline Common causes & Common causes \\
Pneumonia & Sepsis \\
Aspiration of gastric contents & Severe trauma with shock and \\
& multiple transfusions \\
Less common causes & Less common causes \\
Pulmonary contusion & Cardiopulmonary bypass \\
Fat emboli & Drug overdose \\
Near drowning & Acute pancreatitis \\
Inhalational injury & Transfusion of blood products \\
Reperfusion pulmonary oedema after & \\
transplantation or pulmonary embolectomy & \\
\hline
\end{tabular}

ARDS, acute respiratory distress syndrome. immunosuppression, ${ }^{14}$ and obesity ${ }^{28}$ are all associated with the development of ALI, whereas diabetes mellitus appears to be protective. $^{29}$ It is unclear whether this is due to diabetes per se or the anti-inflammatory effect of insulin. Ethnic variations in mortality and outcome with higher reported mortality in black populations are well recognised, and this was thought to be due to an increased severity of illness at presentation. ${ }^{30}$

\section{Morbidity after survival}

Patients who survive any critical illness frequently have significant psychological and physical morbidity. Although lung function parameters tend to recover well in ARDS patients, residual physical limitations and a poor quality of life are common. ${ }^{31}$ Depression, anxiety and post-traumatic stress disorder (PTSD) are also very common; even after 8 years, psychiatrist diagnosed PTSD is reported in up to a quarter of patients. $^{32}$ Risk factors for depression at 1 year are alcohol dependence, female gender and younger age; risk factors for developing anxiety are lower $\mathrm{PaO}_{2} / \mathrm{FiO}_{2}$ ratio and duration of mechanical ventilation. ${ }^{33}$ Cognitive impairment with reduced memory, attention and task execution is also common. ${ }^{34}$ Such morbidity has a significant economic burden and the development of physical and psychological rehabilitation strategies are important to improve outcome in ARDS/ALI survivors.

\section{PATHOPHYSIOLOGY}

ARDS/ALI is characterised by an overwhelming inflammatory process leading to alveolar epithelial and vascular endothelial injury in the lung which can be infective and non-infective in origin. During the initial acute phase of ARDS there is alveolar flooding with protein-rich fluid due to increased vascular permeability. Alveolar epithelial injury of type I cells contributes to the pulmonary oedema and the breakdown of this epithelial barrier exposes the underlying basement membrane, predisposing to bacteraemia and sepsis. Injury to type II alveolar cells leads to impaired surfactant synthesis and metabolism resulting in increased alveolar surface tension and alveolar collapse. ${ }^{1}$ Histopathologically there is diffuse alveolar damage with neutrophil infiltration, alveolar haemorrhage, and hyaline membrane formation. ${ }^{35}$ The acute phase is followed by a fibroproliferative phase in some with various degrees of fibrosis, neovascularisation and later resolution. ${ }^{36}$ However, these stages can often overlap. Vascular injury and remodelling may lead to pulmonary arterial hypertension which may compromise right ventricular function, exacerbating hypoxaemia and leading to poor clinical outcome. ${ }^{1}$

Neutrophils play a critical role in the pathogenesis of ALI/ ARDS and when activated release harmful mediators including cytokines, proteases, reactive oxygen species, and matrix metalloproteinases leading to further damage. ${ }^{37}$ Certain cytokines such as interleukin 1 (IL1), IL6, IL8, and tumour necrosis factor (TNF) are pro-inflammatory and may exacerbate lung injury.

Coagulation cascade abnormalities are characteristic in ALI/ ARDS with an imbalance in both pro- and anticoagulation factors. For example, protein $\mathrm{C}$ concentrations are low in plasma and lung oedema fluid in ARDS patients. ${ }^{38}$ These abnormalities may offer potential therapeutic targets for patients with ALI/ARDS in the future.

\section{DIFFERENTIAL DIAGNOSIS AND DIAGNOSTIC TOOLS}

Many respiratory conditions can mimic ARDS and attempts should be made to exclude other causes of respiratory failure to ensure appropriate treatment. Box 1 shows other potential 
Box 1 Differential diagnosis of acute respiratory distress syndrome

Acute cardiogenic pulmonary oedema

- Other causes of flash pulmonary oedema:

- Renal artery stenosis

- High altitude

- Drugs (eg, naloxone)

- Head injury

- Lymphangitis carcinomatosa

- Pulmonary veno-occlusive diseases

- Pulmonary vasculitis

- Acute presentation of idiopathic interstitial lung diseases

- Acute hypersensitivity pneumonitis

- Acute eosinophilic pneumonia

diagnoses with similar clinical findings. The following investigative tools are generally utilised to facilitate the diagnosis and management of patients with ARDS.

\section{Imaging}

The diagnosis of ARDS is clinical and hinges upon the recognition of a precipitating cause, with radiological and laboratory parameters to aid diagnosis. CXR is a cheap and helpful tool for the diagnosis of ARDS and to exclude other common conditions causing hypoxaemia which require alternative treatments. Typical changes on CXR are bilateral patchy infiltrates. These may take time to evolve and are non-specific and recognition is subject to significant inter-observer variability. ${ }^{910}$ Cardiomegaly, bilateral upper lobe vascular diversion and effusions are more suggestive of cardiac failure than ARDS. ${ }^{39}$

CT scanning can be used to differentiate ARDS from other less common conditions and interstitial processes, and may prevent invasive investigations such as open lung biopsy which are very rarely used. CT is also more specific than plain chest radiograph. Since CT imaging in ARDS has become more common, the homogeneous distribution of the disease suggested by the plain chest radiograph has been disputed. Dependent areas have been shown to be affected more than the apices. ${ }^{40} \mathrm{CT}$ has also been used for quantitative evaluation of lung recruitment manoeuvres. ${ }^{40}$ The major disadvantage of CT scan is the risks involved with patient transfers. Other disadvantages are a larger radiation dose than CXR and the associated cost.

Positron emission tomography with $\left({ }^{18} \mathrm{~F}\right)$ fluorodeoxyglucose (FDG-PET) detects inflammatory cells and can assess lung inflammation. ${ }^{41}$ At present this is a research tool and does not have a clinical role. Future use of this non-invasive technique in routine practice for the management of ARDS patients is likely to be severely limited primarily due to lack of resources.

Ultrasonography is a helpful tool that can be performed at the bedside without radiation exposure. Thoracic ultrasound is widely used for diagnostic and therapeutic intervention in patients with pleural effusions and pneumothoraces. The value of ultrasonography as a method for assessment in lung recruitment following application of PEEP is promising and further studies are needed to evaluate this. ${ }^{42}$

\section{Bronchoalveolar lavage}

Bronchoalveolar lavage (BAL) is used in patients with ARDS to improve targeting of antimicrobial therapy. This is usually a well tolerated procedure in critically ill patients but can be associated with transient worsening of hypoxaemia and haemodynamic instability. ${ }^{43}$ Occasionally BAL may not be practical in severe hypoxaemic patients. Quantitative BAL involves using larger volumes of saline $(100-300 \mathrm{ml})$ and is rarely performed due to practical issues of patient stability and the lack of appropriate processing and analysis facilities in most hospital laboratories. In ARDS, the lavage fluid is usually very cellular and predominated by neutrophils in the early stages. ${ }^{44}$ Eosinophils may be present at later stages, but if present in a high proportion in the early stages of the disease may suggest eosinophilic pneumonia. Lymphocytosis, if present disproportionally, suggests hypersensitivity pneumonitis or cryptogenic organising pneumonia. ${ }^{45}$ Diffuse alveolar haemorrhage may mimic ARDS and in this instance BAL can be diagnostic. BAL is a particularly useful tool in identifying atypical pathogens in immunocompromised patients with lung injury. BAL is also helpful as a research tool to study novel inflammatory markers from bronchial fluid and may provide insights into potential therapeutic targets in the future. Transbronchial and open lung biopsies are reserved for patients with atypical presentation who need histological confirmation and are rarely performed.

\section{Haemodynamic monitoring and assessment}

Pulmonary artery catheters (PAC) were widely used in ICUs following their development in the early 1970s. They were used to assist in the diagnosis of ARDS and to guide fluid management. Although AECC criteria endorsed the pulmonary artery occlusion pressure as one of the components of the diagnostic criteria for $\mathrm{ARDS},{ }^{3} \mathrm{PAC}$ readings are subject to significant interobserver variability and therefore erroneous interpretations. ${ }^{46}$ While PAC has been used by many to guide management in ARDS, there is no evidence to suggest routine use improves outcome. ${ }^{47}$ Due to this lack of evidence, difficulty in interpretation of measurements, risks of procedure and the development of other less invasive techniques have resulted in the decline of PAC usage over recent years.

Other less invasive haemodynamic monitoring procedures such as oesophageal Doppler aortic velocimetry and arterial wave form analysis using lithium (LiDCO) or thermodilution (PiCCO) provide alternatives to PAC in the guidance of fluid management in critically ill patients. The utility of these in the management of ARDS patients has not been evaluated in randomised controlled trials.

Transthoracic echocardiography is a rapid non-invasive tool for the assessment of cardiac function that may provide additional information in the management of ARDS patients. Although very useful in some cases, images are often of limited quality and diagnostic accuracy in ventilated patients. ${ }^{48}$

\section{Biomarkers}

Various inflammatory mediators that reflect epithelial and endothelial injury, inflammation and coagulation abnormalities in ALI have been investigated as potential biomarkers to assist diagnosis and prognostication in ALI. These include IL6, IL8, tumour necrosis factor receptor-1 (TNFR-1), von Willebrand factor (VWF), surfactant protein D (SP-D), intercellular adhesion molecule-1 (ICAM-1), protein C, and plasminogen activator inhibitor-1 (PAI-1). Although some of these biomarkers correlate with mortality, ventilator free days and duration of organ failure, none of the currently available biomarkers are rigorous enough for clinical outcome prediction. When used in combination with clinical variables, plasma IL8 and SP-D are better predictors of clinical outcome than any single biomarker or clinical parameter alone. ${ }^{49}$ Brain natriuretic peptide (BNP) may 
have diagnostic value, and at lower levels may help to exclude cardiogenic pulmonary oedema. ${ }^{50}$

\section{TREATMENT}

The treatment of ARDS involves general supportive measures necessary for all critically ill patients (eg, infection control, early enteral nutrition, stress ulcer prophylaxis, and thromboprophylaxis) combined with focused ventilatory strategies and appropriate treatment of the underlying conditions. There are no effective pharmacological therapies for ARDS. The following section is a review of key therapies that have been trialled in patients with ARDS and ALI. Table 3 illustrates the adopted treatment strategies for patients with ARDS/ALI in current clinical practice.

\section{Ventilation}

Low tidal volume ventilation/protective ventilation

The main supportive therapy for ARDS is positive pressure mechanical ventilation which helps to ensure adequate oxygenation. Early ventilation strategies involved volume controlled ventilation with tidal volume $(\mathrm{Vt})$ of $10-15 \mathrm{ml} / \mathrm{kg}$ to achieve 'normal' arterial blood gases. However, ventilation itself can cause lung injury. A landmark trial conducted in the late 1990s by the ARDS Network compared conventional Vt of $12 \mathrm{ml} / \mathrm{kg}$ with low Vt of $6 \mathrm{ml} / \mathrm{kg}$ and permissive hypercapnia. A $9 \%$ absolute mortality reduction was found in the low Vt ventilation group along with reduced pulmonary and circulating inflammatory cytokines. ${ }^{17}$ In this study, Vt was calculated based on ideal body weight (IBW) with targeted plateau pressures of $<30 \mathrm{~cm}$ $\mathrm{H}_{2} \mathrm{O}$ and permissive hypercapnia. This study produced a significant impact in our current ventilatory practices and has been confirmed by a subsequent study in which patients who were ventilated with higher Vt and lower PEEP had increased ICU and hospital mortality. ${ }^{51}$ A recent trial in patients with respiratory failure without ALI also demonstrated low Vt ventilation to be protective, preventing ALI and associated with a reduction in the release of inflammatory cytokines. This study was stopped early due to an increased incidence of lung injury in patients ventilated with higher $\mathrm{Vt}^{52}$ Taken together, these studies demonstrate the importance of using lower $\mathrm{Vt}$ to ventilate the injured lung as opposed to aiming to normalise blood gases variables.

Earlier concerns of a possible need for increased sedation and haemodynamic compromise, requiring increased cardiovascular support in patients ventilated with low Vt, prevented many physicians from practising this strategy. However, studies addressing these concerns have shown that low TV ventilation is a safe strategy and should be adopted in the management of patients with ARDS/ALI. ${ }^{53-55}$

\section{The level of PEEP}

The optimal level of PEEP in ventilated patients with ARDS/ALI remains controversial. PEEP helps to recruit alveolar units and reduces alveoli collapse due to alveolar flooding and thereby reduces ventilation perfusion mismatch. The level of PEEP needed to achieve optimal recruitment without causing alveolar over-distension and damage is not established. Three large clinical trials conducted to determine 'best PEEP' in patients with ALI showed clinical improvement but no mortality benefit when using high PEEP in comparison with low PEEP $\left(14 \mathrm{~cm} \mathrm{H}_{2} \mathrm{O}\right.$ vs approximately $\left.8 \mathrm{~cm} \mathrm{H}_{2} \mathrm{O}\right) .{ }^{18} 56 \quad 57 \mathrm{~A}$ meta-analysis of these trials confirmed this finding of no mortality benefit, but when patients with ARDS were analysed separately $\left(\mathrm{PaO}_{2} / \mathrm{FiO}_{2}\right.$ $<200 \mathrm{~mm} \mathrm{Hg}$ ) there was a statistically significant improvement in survival in the higher PEEP group. ${ }^{58}$

The percentage of potentially recruitable lung is variable among patients and in the absence of recruitable lung, application of higher levels of PEEP may be harmful. This may partly explain the results of these clinical trials. ${ }^{59}$ Methods that have been utilised to assess recruitability and the response to PEEP include CT of the thorax, ${ }^{60}$ determination of oesophageal pressure $^{61}$ and thoracic ultrasound. ${ }^{62}$ Due to the heterogeneous nature of this disease, the response to PEEP should be

Table 3 Current therapeutic strategies available for the management of patients with ARDS/ALI (general supportive measures are not included)

\begin{tabular}{llll}
\hline Measures & Indication & Benefit & Caution \\
\hline
\end{tabular}

Lung protective ventilation with:

1) Low tidal volume $(6 \mathrm{ml} / \mathrm{kg})$

2) Moderate PEEP as per ARDS

Network guidance ${ }^{47}$

All ARDS/ALI patients

3) Plateau pressure of $<30 \mathrm{~cm} \mathrm{H}_{2} \mathrm{O}$

Prone positioning

High frequency oscillatory ventilation

Severe hypoxaemia

Severe hypoxaemia

Conservative fluid strategies

All ARDS/ALI patients

Low dose early corticosteroids

ECMO
Early ARDS

Severe hypoxaemia
Severe ARDS
Improves mortality

Reduces circulating inflammatory cytokines

Improves oxygenation

May provide survival benefit in patients with severe ARDS

Improves oxygenation

mproves lung function

Reduces the duration of mechanical ventilation

Improves oxygenation

May provide survival benefit

May improve survival when patients transferred

Relatively contraindicated in

patients with high pressure

ventilatory support for $>7$ days
Potential for de-recruitment

May need increased sedation Haemodynamic deterioration

Pressure sores

Endotracheal tube displacement Nursing issues

May produce higher mean pulmonary airway pressures (mPaws) and risk of pneumothorax

May need heavy sedation with paralysis Cardiovascular instability

Renal failure

ICU myopathy and neuropathy

Do not give after 14 days of onset

Risk of infection

Risks of haemorrhage (in particular ICH), risk of large invasive lines

Practically challenging

Patient transfer to specialist unit 
individually assessed when applying higher PEEP, and the utility of various methods as predictors of recruitability in day-to-day practice needs to be established. The ARDS Network has developed a grid of applicable PEEP according to oxygenation which is a valuable guide for estimation of PEEP required. ${ }^{18}$

\section{Recruitment manoeuvres}

While low tidal volume ventilation is lung protective, it may exacerbate lung atelectasis and worsen hypoxia. Various alveolar recruitment manoeuvres have been used to open or recruit collapsed alveoli. These involve either a steady or rapid increase in PEEP or inspiratory holds to increase transpulmonary pressures. A systematic review of 1185 patients suggested significant improvement in oxygenation after a recruitment manoeuvre. This effect, however, was transient and frequent complications were observed including hypotension and associated desaturation. ${ }^{63}$ Although recruitment manoeuvres can improve oxygenation without causing cardiovascular compromise or barotraumas, they need to be individualised, and the lack of standardisation remains a major issue in assessing this treatment modality.

\section{High frequency oscillatory ventilation}

High frequency oscillatory ventilation (HFOV) is an unconventional way of ventilation whereby a piston pump oscillates at a frequency of $3-10 \mathrm{~Hz}$, generating pressure swings leading to small Vt with a high respiratory rate. The mean airway pressure is slightly higher than in conventional ventilation, but the pressure differences throughout the respiratory cycle are smaller. The small Vt generated, coupled with higher mean airway pressures, provide continued alveolar recruitment. HFOV is therefore an intuitively attractive method of ventilating ARDS patients. ${ }^{64}$ However, to date there are few studies involving small numbers of patients comparing HFOV to conventional ventilation. A recent meta-analysis suggested a trend towards mortality benefit and more ventilator free days. The results of this analysis need to be interpreted cautiously as the main study contributing to the meta-analysis used high $\mathrm{Vt}$ in the control group rather than current lung protection ventilation techniques. ${ }^{65} \mathrm{~A}$ large multicentred clinical study (OSCAR) is currently underway, which may indicate whether there is a definitive role of HFOV in patients with ARDS. In the meantime, HFOV remains as a rescue mode of ventilation for patients with severe hypoxaemic ARDS.

\section{Partial liquid ventilation}

Partial liquid ventilation (PLV) is a unique method of ventilation where the lungs are partially filled with an inert liquid called perflourocarbon which has a superior oxygen dissolving capacity to blood and facilitates gaseous exchange. Patients are mechanically ventilated in the usual way. Although there is improvement in gaseous exchange and reduced lung injury in animal models with $\mathrm{PLV}^{66}$ a randomised controlled trial failed to show any mortality benefit in ARDS patients. ${ }^{67}$ This is not a recommended ventilation strategy for ALI/ARDS patients.

\section{Extracorporeal membrane oxygenation}

In the UK extracorporeal membrane oxygenation (ECMO) is only performed by specialised centres. ECMO involves oxygenation of the patient's blood outside the body via a membrane oxygenator which acts as an artificial lung, allowing adequate gaseous exchange without vigorous mechanical ventilation. An earlier study conducted in the 1970s showed no survival benefit, with overall mortality exceeding $>90 \%{ }^{68}$ A UK clinical trial
(CESAR) randomised eligible patients with ARDS to 'conventional' treatment in the referring centre or transfer to the specialist centre for ECMO. This study showed a survival advantage in the ECMO group (63\% for ECMO vs $47 \%$ for controls). ${ }^{69}$ However, the study was criticised for not having a standardised protocol management for the control group and because some patients in the treatment arm did not receive ECMO. The major risks associated with ECMO are the risks of transfer of seriously ill patients, complications of large bore vascular access, and bleeding due to anticoagulation. Currently ECMO remains an option as a rescue therapy for patients with refractory hypoxaemia. Its use is likely to be limited to specialised centres.

\section{Prone positioning}

Prone positioning results in a consistent improvement in oxygenation in patients with hypoxic respiratory failure. The possible mechanisms for improved oxygenation are: recruitment of dependent lung units, redistribution of blood flow to the more unaffected lung regions, reducing ventilation perfusion mismatch, ${ }^{70}$ minimising compression of lung from anterior mediastinal structures, ${ }^{78}$ and facilitation of respiratory secretion clearance. Four large randomised controlled trials have consistently shown improvements in oxygenation without survival benefit or reduction in duration of ventilation. ${ }^{72} \mathrm{~A}$ recent metaanalysis performed by Gattinoni et al suggests survival benefit in a subgroup of patients with severe ARDS $\left(\mathrm{PaO}_{2} / \mathrm{FiO}_{2}<100\right.$ $\mathrm{mm} \mathrm{Hg}$ ). They concluded that prone positioning should be considered for patients with severe hypoxaemia including ARDS. ${ }^{73}$ The common adverse effects of prone positioning are pressure sores and tube displacement. Prone positioning may be considered in patients with severe ARDS to improve oxygenation in centres with capable nursing expertise.

\section{Pharmacological therapies}

Pharmacotherapies have a very limited role in the management of ARDS. So far there is no effective medical treatment that improves survival for adult patients with ARDS, although exogenous surfactant is beneficial in the paediatric population.

\section{Neuromuscular agents}

Neuromuscular agents (NMA) can be used to improve patientventilator synchrony and assist mechanical ventilation in patients with severe hypoxaemia. There is evidence that using NMA in patients with severe ARDS $\left(\mathrm{PaO}_{2} / \mathrm{FiO}_{2}<150 \mathrm{~mm} \mathrm{Hg}\right)$ improves oxygenation and reduces inflammatory cytokines. ${ }^{74} 75$ A phase IV randomised controlled trail comparing cis-atracurium with placebo for $48 \mathrm{~h}$ in patients with severe ARDS $\left(\mathrm{PaO}_{2} / \mathrm{FiO}_{2}\right.$ $<150 \mathrm{~mm} \mathrm{Hg}$ ) showed improved adjusted 90 day survival rate and increased ventilator fee days in the cis-atracurium group without significant increase in muscle weakness. ${ }^{76}$ It is not clear whether the observed benefit was due to neuromuscular paralysis alone, possible additional anti-inflammatory effects, or a possible reduction in oxygen consumption. Paralysing patients with NMA can be associated with critical care neuromyopathy, longer weaning times, longer ICU stays, and a higher mortality and they therefore need to be used cautiously. ${ }^{77}$ From this evidence, it is not possible to recommend routine use of NMA beyond the usual indications. Further studies are necessary to evaluate the routine use of NMA in ARDS/ALI.

\section{Vasodilators}

\section{Inhaled nitric oxide}

Inhaled nitric oxide (NO) is an endogenous vasodilator. When inhaled it reduces $\mathrm{V} / \mathrm{Q}$ mismatch and improves oxygenation by 
selective pulmonary vasodilatation in alveolar units that are ventilated. ${ }^{78}$ It has been used in clinical trials in patients with hypoxic ventilatory failure, ALI, and ARDS. Inhaled $\mathrm{NO}$ also reduces elevated pulmonary vascular resistance in patients with ARDS. ${ }^{79}$ Adverse effects of inhaled $\mathrm{NO}$ are methaemoglobinaemia, cytotoxic nitrogen products (nitrogen dioxide), and renal failure. ${ }^{80}$ A Canadian survey in 2004 reported that up to $30 \%$ of critical care physicians were using inhaled $\mathrm{NO}$ in selected patients with ARDS, ${ }^{81}$ suggesting widespread usage as rescue therapy despite the lack of evidence. A Cochrane review of 14 clinical trials with 1303 patients (which included three paediatric and one combined adult and paediatric study) showed only a transient improvement in oxygenation with no survival benefit or increase in ventilator free days. Furthermore, no improvement was seen in secondary outcomes such as length of ICU or hospital stay, and increased renal impairment was noted in the inhaled $\mathrm{NO}$ treated group. ${ }^{82}$ Current use is declining due to the poor outcome data and escalating costs of using inhaled NO. Its use is not recommended as routine therapy but may be considered for improvement of oxygenation in patients with refractory hypoxaemia.

\section{Prostanoids}

Prostacyclins are arachidonic acid derivatives that cause pulmonary vasodilatation and are used to treat patients with primary pulmonary hypertension. They have additional immunomodulatory effects such as reducing neutrophil adhesion, and inhibition of neutrophil, macrophage and platelet activation. ${ }^{83}$ Nebulised prostacyclin $\left(\mathrm{PGI}_{2}\right)$ has comparable effects in improving oxygenation, pulmonary vasodilatation and shunt reduction when compared with inhaled NO. ${ }^{84}$ Improved oxygenation has been seen in a paediatric study, ${ }^{85}$ but this has not yet been demonstrated in adult patients with ARDS.

Intravenous prostaglandin $\left(\mathrm{PGE}_{1}\right)$ has been evaluated in a Cochrane systematic review which identified seven studies including a total of 697 patients. These studies were difficult to compare due to protocol and drug formulation differences, but no mortality benefit was seen and more hypotension, arrhythmias and hypoxia occurred in the study group. ${ }^{86}$ Clinically prostanoids are rarely used and not recommended for routine practice.

\section{Anti-inflammatory agents \\ Steroids}

ARDS is characterised by a profound inflammatory process followed by fibro-proliferative changes; using steroids to reduce this inflammation or to moderate the fibrotic recovery is an obvious approach that has been tried in several clinical studies. The dose of corticosteroids, duration of treatment, and the timing of initiation in both prevention and treatment of ARDS has been evaluated. Studies of ARDS prevention for at risk patients suggest that there is no preventative effect conferred by the use of high dose short duration courses of steroids. ${ }^{87}$ High dose short duration steroids also have no mortality benefit in early ARDS. ${ }^{88}$ In a phase III study, the ARDS Network investigators assessed the effect of steroids in the late stage fibrotic phase of ARDS (after 7 days of onset) and again showed no mortality benefit in the treatment group, with a higher mortality in patients treated 14 days after onset. ${ }^{89}$ A study by Meduri et al showed improved ICU mortality, LIS, lower infection rate, and shorter duration of mechanical ventilation and ICU stay when low dose corticosteroids were commenced in the early stages of ARDS. However, this study was limited by small numbers and methodological issues, including a 2:1 randomisation allocation ratio and frequent crossovers. Moreover, an increased number of patients with catecholamine dependent shock in the treatment group may have biased the mortality outcome in this group. ${ }^{90}$

Further larger randomised controlled trials are needed to assess the effect of low dose corticosteroids in patients with early ARDS. From the available evidence, corticosteroids are not indicated for prevention, but low dose steroids $(1-2 \mathrm{mg} / \mathrm{kg}$ methylprednisolone) may be considered in patients with severe early $(<72 \mathrm{~h})$ ARDS. The dose titration and the duration of treatment remains a contentious issue. While prolonged use of corticosteroids may moderate fibrotic recovery, this should be balanced against the deleterious effects of steroids. It is not recommended to initiate corticosteroids beyond 14 days after the onset of ARDS.

\section{Ketoconazole}

Ketoconazole is an imidazole based antifungal medication which inhibits the synthesis of thromboxane $A_{2}$, a potent vasoconstrictor involved in platelet aggregation and neutrophil recruitment. ${ }^{91}$ It is also known to reduce alveolar macrophage inflammatory mediator ${ }^{92}$ and was therefore assessed for its role as an anti-inflammatory agent in ARDS. Although early preventive studies suggested benefit, ${ }^{93} 94$ a phase III study conducted in 2000 by the ARDS Network showed no improvement in mortality or secondary outcome measures. ${ }^{95}$ Ketoconazole is not recommended for the treatment of ARDS/ALI.

\section{Lysofylline and pentoxifylline}

Pentoxifylline is a phosphodiesterase inhibitor and lisofylline is a pentoxifylline derivative with anti-inflammatory properties. Lisofylline reduces elevated circulating oxidised free fatty acids levels, seen in patients with ARDS, and inhibits neutrophil accumulation as well as reducing pro-inflammatory cytokines (TNF $\alpha$, IL1, and IL6). While animal studies showed promising results, a phase II/III study conducted by the ARDS Network showed no treatment benefit and a trend towards increased mortality in patients treated with lisofylline. ${ }^{96}$ This is not recommended as treatment for ARDS/ALI.

\section{Sivelestat (neutrophil elastase inhibitor)}

Neutrophil elastase secreted by activated neutrophils is thought to play an important role in endothelial damage and changes in vascular permeability during ALI. Sivelestat is an inhibitor of neutrophil elastase and was studied in a phase II/III randomised controlled trial (STRIVE). Mortality was increased in the treatment arm and the study was stopped prematurely. ${ }^{97}$ Depelestat is another neutrophil elastase inhibitor currently being assessed in ARDS patients in a phase II study, the results of which are expected soon. Neutrophil elastase inhibitors remain an experimental therapy while further results are awaited.

\section{Antioxidants}

Oxygen free radicals produced by activated neutrophils and macrophages are thought to play an important role in the inflammatory pathways that lead to cell damage in patients with ARDS. Glutathione is an antioxidant which is produced in the liver, the levels of which are reduced in alveolar fluid in patients with ARDS. ${ }^{98}$ Glutathionine levels can be replenished by supplementation with its precursor $N$-acetylcysteine. Several small studies have demonstrated no mortality benefit with the use of $N$-acetylcysteine in ALI and ARDS patients. ${ }^{86}$

\section{Fluid management and alveolar fluid clearance}

Optimal fluid management is an essential step in the resuscitation of critically ill patients. While it is important to maintain 
an adequate intravascular pressure to perfuse major organs, raised capillary hydrostatic pressure from excess fluid therapy can lead to worsening of pulmonary oedema in patients with ARDS. ${ }^{99}$ Positive fluid balance is associated with worse clinical outcomes in patients with ARDS. ${ }^{100}$ A phase III study conducted by the ARDS Network compared liberal versus conservative fluid strategy in patients with ALI. Despite showing no difference in mortality between the groups, the conservative group had improved oxygenation, LIS, and shortened duration of mechanical ventilation without any increase in other organ failures. ${ }^{19}$ We recommend a conservative fluid management approach, once resuscitation is complete, with the aim being to achieve cumulative neutral balance without compromising cardiovascular and renal variables. Some patients accumulate a significant positive fluid balance during the resuscitation phase, and use of diuretics (after resolution of haemodynamic instability) to achieve a sustained negative balance may be valuable. Careful monitoring of renal function and other indices of perfusion is important if this strategy is adopted.

The resolution of ARDS depends on the adequate clearance of the alveolar oedema. Defective alveolar fluid clearance is associated with decreased survival in ARDS patients. ${ }^{101} 102$ The role of $\beta 2$ agonists in assisting alveolar fluid clearance has been investigated using salbutamol in ARDS patients. A small study demonstrated reduced extravascular lung water and a trend towards survival benefit. ${ }^{103}$ The effect of $\beta 2$ agonists in ARDS/ ALI has been further investigated in phase II/III multicentre studies in the USA with aerolised albuterol (ALTA) and in the UK with intravenous salbutamol (BALTI-2). Both studies were stopped prematurely. Preliminary data suggest that $\beta 2$ agonists provide no survival benefit in ARDS/ALI and in fact may be associated with increased mortality. ${ }^{20} \beta 2$ agonists are not recommended as part of therapy for patients with ARDS/ALI.

\section{Immunonutrition}

Nutritional input has been increasingly valued in critically ill patients and early enteral nutrition is generally advised. Manipulation of nutrition with supplementation of fish oil based omega-3 fatty acids, eicosapentanoic acid (EPA), docosahexaenoic acid (DHA), and gamma-linolenic acid (GLA) in borage oil are thought to reduce arachidonic acid availability for the generation of inflammatory pathways. Supplementation with EPA and GLA has resulted in alveolar neutrophil de-recruitment, improved gaseous exchange, and reduction in duration of mechanical ventilation. ${ }^{104} \mathrm{~A}$ recent systematic review to assess immunonutrition in critically ill patients showed significant reduction in mortality, secondary infections and length of hospital stay with fish oil based immunonutrition in the ICU setting. ${ }^{105}$

A recent phase III clinical trial conducted by the ARDS Network supplementing omega-3 fatty acids, GLA and antioxidants in patients with ALI (OMEGA) showed no mortality benefit. $^{21}$ Further trials are currently underway to assess the effect fish oil in ARDS patients. This form of nutrition remains experimental and further studies are needed to elucidate the effects of various types of immunonutrition for inflammatory modulation in patients with ARDS/ALI.

\section{Exogenous surfactants}

Pulmonary surfactant is a complex mixture of phospholipids, proteins and neutral lipids produced by alveolar type II cells. Surfactant helps to maintain alveolar surface tension and is also involved in the host immune response. ${ }^{106}$ Bronchial lavage surfactants recovered from patients with ARDS show changes in phospholipids composition and decreased levels of surfactant proteins. ${ }^{107-109}$ A number of clinical trials have tested the hypothesis that administration of exogenous surfactant confers clinical benefit in adult patients with ARDS, but in contrast to the literature in newborns and children, no mortality benefit has been demonstrated. ${ }^{110}$ Limitations of these studies include insufficient surfactant delivery, lack of incorporation of hydrophilic surfactant proteins and, possibly most importantly, no targeting of populations who might be most likely to benefit (eg, where there is reduced production rather than inactivation or increased breakdown due to hydrolysis and/or oxidation). Novel techniques utilising stable isotope labelling of surfactant precursors, to assess surfactant synthesis and metabolism, ${ }^{111}$ open up the possibility of characterising and targeting patients with reduced synthesis who may most likely benefit from exogenous surfactant. However, at present exogenous surfactant has no added value in the management of adult patients with ARDS.

\section{Mesenchymal stem cells}

Mesenchymal stem cells (MSC) are bone marrow derived stem cells with a capacity to differentiate into many cell types. Their therapeutic importance is under investigation in many diseases including lung injury. In animal models with lung injury, intravenous MSC lead to favourable outcome with reduction in inflammation, pro-inflammatory cytokines and lung oedema. In ex vivo human lung models of endotoxin induced lung injury, administration of MSC resulted in improved alveolar fluid clearance with quantitative increase in keratinocyte growth

Table 4 Potential therapies for ALI/ARDS under clinical evaluation

\begin{tabular}{ll}
\hline Therapy & Action \\
\hline 1. Anti-tissue factor antibody & To reduce procoagulant activity and inflammation \\
2. CytoSorb haemoperfusion device for IL6 & Removal of IL6 and hence reduce inflammation \\
3. Depelestat (neutrophil elastase inhibitor) & Anti-inflammatory \\
4. Fish oil & Immunonutrition \\
5. Granulocyte macrophage colony stimulating factor & Promoting alveolar epithelial cell proliferation and repair \\
6. Nebulised heparin & To reduce pulmonary coagulation activation and vascular \\
& permeability \\
7. Interferon $\beta$ & To reduce vascular leakage \\
8. Insulin & Anti-inflammatory \\
9. Keratinocyte growth factor & To promote alveolar epithelial proliferation and repair \\
10. P38 $\alpha$ mitogen-activated protein kinase inhibitor & Anti-inflammatory \\
11. Statins & Anti-inflammatory \\
\hline
\end{tabular}

ALI, acute lung injury; ARDS, acute respiratory distress syndrome. 


\section{Main messages}

- ARDS is a clinical syndrome characterised by severe hypoxaemic respiratory failure.

- Despite limitations, the AECC diagnostic criteria is a simple screening tool for patient identification.

- Assessment of the underlying condition with appropriate treatment is an essential part of management strategy.

- Lung protective ventilation with low tidal volume $(6 \mathrm{ml} / \mathrm{kg})$, moderate PEEP and plateau pressure limitation $<30 \mathrm{~cm} \mathrm{H}_{2} \mathrm{O}$ improves patient survival.

- General supportive measures are likely to have contributed in survival benefit and should not be overlooked.

- A conservative fluid management strategy should be adopted.

- Severe ARDS patients may have beneficial effects from the measures such as recruitment manoeuvres, prone positioning, higher PEEP, and transfer to a specialist centre in difficult cases (eg, ECMO).

factor (KGF). KGF is a cytokine and a potent mitogen which specifically acts on epithelial cells, and in lung injury models it is protective and induces type II cell proliferation and oedema clearance. ${ }^{112}$ Human studies with MSC are still awaited. A single centre phase II study is underway to assess the effect of intravenous KGF in ALI patients.

\section{DIFFICULTIES WITH ARDS TRIALS AND FUTURE DIRECTIONS}

Pharmacological clinical trials in ARDS are limited by the heterogeneous nature of patients and the lack of direct translational animal models that adequately represents ARDS pathogenesis in humans. Subgroups of patients have been found to benefit from certain therapies in patients with severe ARDS, ${ }^{58} 73$ but so far no medical treatment has been shown to improve overall survival. Nevertheless, future ARDS therapies

\section{Current research questions}

1. Effective identification of useful biomarkers and genetic markers for diagnosis, phenotypic characterisation, and prognostic assessment.

2. Role of various inflammatory pathways and possible targets for treatment-for example, insulin, statin, depelestat, antiILI, etc.

3. Use of stem cells for epithelial and endothelial repair.

4. The use of potent mitogenic cytokines such as KGF and GM-CSF in epithelial repair and effective alveolar oedema clearance.

5. Modulation of procoagulant activity in the lung.

6. Newer surfactant preparations:

- withstanding hydrolysis or breakdown

- in certain phenotypes (eg, intrinsic vs extrinsic or patients with reduced synthesis)

- use of potential carriers to improve delivery

7. Effective removal of cytokines from whole blood via cytoabsorb haemoperfusion to reduce inflammation.

8. The clinical effects of various immunonutrition on ARDS/ALI.

9. The clinical effectiveness of the newer lung assisting devices in advanced lung protective ventilation.

\section{Key references}

Ashbaugh DG, Bigelow DB, Petty TL, et al. Acute respiratory distress in adults. Lancet 1967;2:319-23.

- Bernard GR, Artigas A, Brigham KL, et al. The AmericanEuropean Consensus Conference on ARDS. Definitions, mechanisms, relevant outcomes, and clinical trial coordination. Am J Respir Crit Care Med 1994;149(3 Pt 1):818-24.

- The Acute Respiratory Distress Syndrome Network. Ventilation with lower Vt as compared with traditional Vt for acute lung injury and the acute respiratory distress syndrome. N Engl J Med 2000;342:1301-8.

- Wiedemann HP, Wheeler AP, Bernard GR, et al. Comparison of two fluid-management strategies in acute lung injury. N Engl J Med 2006;354:2564-75.

- Briel M, Meade M, Mercat A, et al. Higher vs lower positive end-expiratory pressure in patients with acute lung injury and acute respiratory distress syndrome: systematic review and meta-analysis. JAMA 2010;303:865-73.

may involve single or combination treatments that involve targeting inflammatory pathways at various levels, minimising vascular dysfunction and oxidative lung injury, and improving alveolar fluid clearance. Cell based therapies with MSC are currently under evaluation and show promising results in animal models. ${ }^{112}$ Statins, insulin and interferon $\beta$ are also currently under evaluation in clinical trials (table 4).

\section{CONCLUSIONS}

ARDS remains a major health burden. Mortality remains high with significant physical and psychosocial morbidity. Therapeutic strategies remain sparse and ongoing trials will hopefully provide further information on future potential treatments. On the other hand, the future looks exciting. Investigators are likely to concentrate on manipulating inflammatory pathways and optimising repair of lung tissue while preventing the development or progression of ALI/ARDS. Improved characterisation of subgroups of patients within this heterogeneous population may also lead to advances.

\section{MULTIPLE CHOICE QUESTIONS (TRUE (T)/FALSE (F): ANSWERS AFTER THE REFERENCES)}

1. In patients with ARDS, mechanical ventilation with low tidal volume improves survival

2. Lymphocytes are predominant cells in bronchoalveolar lavage of patients with early ARDS

3. Respiratory failure is the most common cause of death in ARDS

4. Prone positioning improves oxygenation in ARDS

5. Exogenous surfactant therapy improves oxygenation and survival rates in patients with ARDS

Competing interests None.

Provenance and peer review Not commissioned; externally peer reviewed.

\section{REFERENCES}

Ware LB, Matthay MA. The acute respiratory distress syndrome. N Engl J Med 2000;342:1334-49.

2. Ashbaugh DG, Bigelow DB, Petty $\mathrm{TL}$, et al. Acute respiratory distress in adults. Lancet 1967;2:319-23.

3. Bernard GR, Artigas A, Brigham KL, et al. The American-European Consensus Conference on ARDS. Definitions, mechanisms, relevant outcomes, and clinical trial coordination. Am J Respir Crit Care Med 1994;149(3 Pt 1):818-24. 
4. Murray JF, Matthay MA, Luce JM, et al. An expanded definition of the adult respiratory distress syndrome. Am Rev Respir Dis 1988;138:720-3.

5. Ferguson ND, Davis AM, Slutsky AS, et al. Development of a clinical definition for acute respiratory distress syndrome using the Delphi technique. J Crit Care 2005;20:147-54.

6. Esteban A, Fernandez-Segoviano P, Frutos-Vivar F, et al. Comparison of clinical criteria for the acute respiratory distress syndrome with autopsy findings. Ann Intern Med 2004;141:440-5.

7. Villar J, Perez-Mendez L, Lopez J, et al. An early PEEP/FIO 2 trial identifies different degrees of lung injury in patients with acute respiratory distress syndrome. $A m \mathrm{~J}$ Respir Crit Care Med 2007:176:795-804.

8. Ferguson ND, Kacmarek RM, Chiche JD, et al. Screening of ARDS patients using standardized ventilator settings: influence on enrollment in a clinical trial. Intensive Care Med 2004;30:1111-16.

9. Rubenfeld GD, Caldwell E, Granton J, et al. Interobserver variability in applying a radiographic definition for ARDS. Chest 1999;116:1347-53.

10. Meade MO, Cook RJ, Guyatt GH, et al. Interobserver variation in interpreting chest radiographs for the diagnosis of acute respiratory distress syndrome. Am J Respir Crit Care Med 2000;161:85-90.

11. Ferguson ND, Frutos-Vivar F, Esteban A, et al. Acute respiratory distress syndrome: underrecognition by clinicians and diagnostic accuracy of three clinical definitions. Crit Care Med 2005;33:2228-34.

12. Rubenfeld GD, Caldwell E, Peabody E, et al. Incidence and outcomes of acute lung injury. N Engl J Med 2005;353:1685-93.

13. Webster NR, Cohen AT, Nunn JF. Adult respiratory distress syndrome-how many cases in the UK? Anaesthesia 1988:43:923-6.

14. Luhr $\mathbf{O R}$, Antonsen $\mathrm{K}$, Karlsson $\mathrm{M}$, et al. Incidence and mortality after acute respiratory failure and acute respiratory distress syndrome in Sweden, Denmark, and Iceland. The ARF Study Group. Am J Respir Crit Care Med 1999;159:1849-61.

15. Hughes M, MacKirdy FN, Ross J, et al. Acute respiratory distress syndrome: an audit of incidence and outcome in Scottish intensive care units. Anaesthesia 2003;58:838-45.

16. Phua J, Badia JR, Adhikari NK, et al. Has mortality from acute respiratory distress syndrome decreased over time? A systematic review. Am J Respir Crit Care Med 2009;179:220-7.

17. Anon. Ventilation with lower tidal volumes as compared with traditional tidal volumes for acute lung injury and the acute respiratory distress syndrome. The Acute Respiratory Distress Syndrome Network. N Engl J Med 2000;342:1301-8.

18. Brower RG, Lanken PN, Maclntyre N, et al. Higher versus lower positive end-expiratory pressures in patients with the acute respiratory distress syndrome. N Engl J Med 2004;351:327-36.

19. Wiedemann HP, Wheeler AP, Bernard GR, et al. Comparison of two fluid-management strategies in acute lung injury. $N$ Engl J Med 2006:354:2564-75

20. Matthay MA, Brower RG, Thompson BT, et al. Randomised, placebo-controlled trial of an aerosolized beta-2 adrenergic agonist (Albuterol) for the treatment of acute lung injury. Am J Res Crit Care Med 2009;179:A2166.

21. Rice TW, Thompson BT, Smoot E, et al. Omega-3 (n-3) fatty acid, gamma-linolenic acid (GLA) and anti-oxidant supplementation in acute lung injury (OMEGA Trial). Crit Care Med 2009:37:A408.

22. Spragg RG, Bernard GR, Checkley W, et al. Beyond mortality: future clinical research in acute lung injury. Am J Respir Crit Care Med 2010;181:1121-7.

23. Stapleton RD, Wang BM, Hudson LD, et al. Causes and timing of death in patients with ARDS. Chest 2005;128:525-32.

24. Montgomery $\mathbf{A B}$, Stager MA, Carrico CJ, et al. Causes of mortality in patients with the adult respiratory distress syndrome. Am Rev Respir Dis 1985;132:485-9.

25. Gao L, Barnes KC. Recent advances in genetic predisposition to clinical acute lung injury. Am J Physiol Lung Cell Mol Physiol 2009;296:L713-25.

26. Berkowitz DM, Danai PA, Eaton S, et al. Alcohol abuse enhances pulmonary edema in acute respiratory distress syndrome. Alcohol Clin Exp Res 2009;33:1690-6.

27. Moss M, Steinberg KP, Guidot DM, et al. The effect of chronic alcohol abuse on the incidence of ARDS and the severity of the multiple organ dysfunction syndrome in adults with septic shock: an interim and multivariate analysis. Chest 1999:116(1 Suppl):97S-8S

28. Gajic 0, Dabbagh 0, Park PK, et al. Early identification of patients at risk of acute lung injury: evaluation of lung injury prediction score in a multicenter cohort study. Am J Respir Crit Care Med 2010;183:462-70.

29. Moss M, Guidot DM, Steinberg KP, et al. Diabetic patients have a decreased incidence of acute respiratory distress syndrome. Crit Care Med 2000;28:2187-92.

30. Erickson SE, Shlipak MG, Martin GS, et al. Racial and ethnic disparities in mortality from acute lung injury. Crit Care Med 2009;37:1-6.

31. Herridge MS, Cheung AM, Tansey CM, et al. One-year outcomes in survivors of the acute respiratory distress syndrome. N Engl J Med 2003;348:683-93.

32. Davydow DS, Desai SV, Needham DM, et al. Psychiatric morbidity in survivors of the acute respiratory distress syndrome: a systematic review. Psychosom Med 2008; 70:512-19

33. Hopkins RO, Key CW, Suchyta MR, et al. Risk factors for depression and anxiety in survivors of acute respiratory distress syndrome. Gen Hosp Psychiatry 2010;32:147-55.
34. Hopkins RO, Weaver LK, Collingridge D, et al. Two-year cognitive, emotional, and quality-of-life outcomes in acute respiratory distress syndrome. Am J Respir Crit Care Med 2005;171:340-7.

35. Bachofen M, Weibel ER. Alterations of the gas exchange apparatus in adult respiratory insufficiency associated with septicemia. Am Rev Respir Dis 1977:116:589-615.

36. Gattinoni L, Bombino M, Pelosi $\mathrm{P}$, et al. Lung structure and function in different stages of severe adult respiratory distress syndrome. JAMA 1994;271:1772-9.

37. Zemans RL, Colgan SP, Downey GP. Transepithelial migration of neutrophils: mechanisms and implications for acute lung injury. Am J Respir Cell Mol Biol 2009;40:519-35.

38. Ware LB, Fang $X$, Matthay MA. Protein $C$ and thrombomodulin in human acute lung injury. Am J Physiol Lung Cell Mol Physiol 2003;285:L514-21.

39. Gluecker T, Capasso P, Schnyder P, et al. Clinical and radiologic features of pulmonary edema. Radiographics 1999;19:1507-31.

40. Gattinoni L, Chiumello D, Cressoni M, et al. Pulmonary computed tomography and adult respiratory distress syndrome. Swiss Med Wkly 2005;135:169-74.

41. Bellani G, Messa C, Guerra L, et al. Lungs of patients with acute respiratory distress syndrome show diffuse inflammation in normally aerated regions: a $\left[{ }^{18} \mathrm{~F}\right]$-fluoro-2-deoxy-D-glucose PET/CT study. Crit Care Med 2009;37:2216-22.

42. Arbelot C, Ferrari F, Bouhemad B, et al. Lung ultrasound in acute respiratory distress syndrome and acute lung injury. Curr Opin Crit Care 2008:14:70-4.

43. Steinberg KP, Mitchell DR, Maunder RJ, et al. Safety of bronchoalveolar lavage in patients with adult respiratory distress syndrome. Am Rev Respir Dis 1993:148:556-61.

44. Nakos G, Kitsiouli El, Tsangaris I, et al. Bronchoalveolar lavage fluid characteristics of early intermediate and late phases of ARDS. Alterations in leukocytes, proteins, PAF and surfactant components. Intensive Care Med 1998:24:296-303.

45. Schwarz MI, Albert RK. "Imitators" of the ARDS: implications for diagnosis and treatment. Chest 2004;125:1530-5.

46. Komadina KH, Schenk DA, LaVeau $\mathrm{P}$, et al. Interobserver variability in the interpretation of pulmonary artery catheter pressure tracings. Chest 1991; 100:1647-54.

47. Wheeler AP, Bernard GR, Thompson BT, et al. Pulmonary-artery versus central venous catheter to guide treatment of acute lung injury. $N$ Engl J Med 2006;354:2213-24.

48. Vignon $\mathbf{P}$, Mentec $\mathrm{H}$, Terre $\mathrm{S}$, et al. Diagnostic accuracy and therapeutic impact of transthoracic and transesophageal echocardiography in mechanically ventilated patients in the ICU. Chest 1994:106:1829-34.

49. Ware LB, Koyama T, Billheimer DD, et al. Prognostic and pathogenetic value of combining clinical and biochemical indices in patients with acute lung injury. Chest 2010;137:288-96.

50. Ware LB, Matthay MA. Clinical practice. Acute pulmonary edema. N Engl J Med 2005;353:2788-96

51. Villar J, Kacmarek RM, Perez-Mendez L, et al. A high positive end-expiratory pressure, low tidal volume ventilatory strategy improves outcome in persistent acute respiratory distress syndrome: a randomized, controlled trial. Crit Care Med 2006; $34: 1311-18$

52. Determann RM, Royakkers A, Wolthuis EK, et al. Ventilation with lower tidal volumes as compared with conventional tidal volumes for patients without acute lung injury: a preventive randomized controlled trial. Crit Care 2010;14:R1.

53. Rubenfeld GD, Cooper C, Carter G, et al. Barriers to providing lung-protective ventilation to patients with acute lung injury. Crit Care Med 2004;32:1289-93.

54. Cheng IW, Eisner MD, Thompson BT, et al. Acute effects of tidal volume strategy on hemodynamics, fluid balance, and sedation in acute lung injury. Crit Care Med 2005; 33:63-70.

55. Kahn JM, Andersson L, Karir V, et al. Low tidal volume ventilation does not increase sedation use in patients with acute lung injury. Crit Care Med 2005:33:766-71.

56. Meade MO, Cook DJ, Guyatt GH, et al. Ventilation strategy using low tidal volumes, recruitment maneuvers, and high positive end-expiratory pressure for acute lung injury and acute respiratory distress syndrome: a randomized controlled trial. JAMA 2008;299:637-45.

57. Mercat A, Richard JC, Vielle B, et al. Positive end-expiratory pressure setting in adults with acute lung injury and acute respiratory distress syndrome: a randomized controlled trial. JAMA 2008;299:646-55.

58. Briel $\mathbf{M}$, Meade $\mathbf{M}$, Mercat $\mathrm{A}$, et al. Higher vs lower positive end-expiratory pressure in patients with acute lung injury and acute respiratory distress syndrome: systematic review and meta-analysis. JAMA 2010;303:865-73.

59. Gattinoni L, Caironi $\mathrm{P}$, Cressoni $\mathrm{M}$, et al. Lung recruitment in patients with the acute respiratory distress syndrome. N Engl J Med 2006;354:1775-86.

60. Gattinoni L, Caironi P, Valenza F, et al. The role of CT-scan studies for the diagnosis and therapy of acute respiratory distress syndrome. Clin Chest Med 2006;27:559-70.

61. Talmor D, Sarge T, Malhotra A, et al. Mechanical ventilation guided by esophageal pressure in acute lung injury. N Engl J Med 2008;359(20):2095-104.

62. Bouhemad B, Brisson H, Le-Guen M, et al. Bedside ultrasound assessment of positive end-expiratory pressure-induced lung recruitment. Am J Respir Crit Care Med 2011;183:341-7.

63. Fan E, Wilcox ME, Brower RG, et al. Recruitment maneuvers for acute lung injury: a systematic review. Am J Respir Crit Care Med 2008;178:1156-63. 
64. Chan KP, Stewart TE, Mehta S. High-frequency oscillatory ventilation for adult patients with ARDS. Chest 2007;131:1907-16

65. Sud S, Sud M, Friedrich J0, et al. High frequency oscillation in patients with acute lung injury and acute respiratory distress syndrome (ARDS): systematic review and meta-analysis. BMJ 2010;340:c2327.

66. Hirschl RB, Parent A, Tooley $\mathrm{R}$, et al. Liquid ventilation improves pulmonary function, gas exchange, and lung injury in a model of respiratory failure. Ann Surg 1995;221:79-88

67. Kacmarek RM, Wiedemann HP, Lavin PT, et al. Partial liquid ventilation in adult patients with acute respiratory distress syndrome. Am J Respir Crit Care Med 2006;173:882-9

68. Zapol WM, Snider MT, Hill JD, et al. Extracorporeal membrane oxygenation in severe acute respiratory failure. A randomized prospective study. JAMA 1979;242:2193-6.

69. Peek GJ, Mugford M, Tiruvoipati R, et al. Efficacy and economic assessment of conventional ventilatory support versus extracorporeal membrane oxygenation for severe adult respiratory failure (CESAR): a multicentre randomised controlled trial. Lancet 2009;374:1351-63

70. Pelosi $\mathbf{P}$, Brazzi L, Gattinoni L. Prone position in acute respiratory distress syndrome. Eur Respir J 2002;20:1017-28.

71. Albert RK, Hubmayr RD. The prone position eliminates compression of the lungs by the heart. Am J Respir Crit Care Med 2000;161:1660-5.

72. Alsaghir AH, Martin CM. Effect of prone positioning in patients with acute respiratory distress syndrome: a meta-analysis. Crit Care Med 2008; 36:603-9.

73. Gattinoni L, Carlesso $E$, Taccone $P$, et al. Prone positioning improves survival in severe ARDS: a pathophysiologic review and individual patient meta-analysis. Minerva Anestesiol 2010;76:448-54.

74. Gainnier $\mathbf{M}$, Roch A, Forel JM, et al. Effect of neuromuscular blocking agents on gas exchange in patients presenting with acute respiratory distress syndrome. Crit Care Med 2004:32:113-19.

75. Forel JM, Roch A, Marin V, et al. Neuromuscular blocking agents decrease inflammatory response in patients presenting with acute respiratory distress syndrome. Crit Care Med 2006:34:2749-57.

76. Papazian L, Forel JM, Gacouin A, et al. Neuromuscular blockers in early acute respiratory distress syndrome. N Engl J Med 2010;363:1107-16.

77. Arroliga A, Frutos-Vivar F, Hall J, et al. Use of sedatives and neuromuscular blockers in a cohort of patients receiving mechanical ventilation. Chest 2005:128:496-506

78. Rossaint R, Falke KJ, Lopez F, et al. Inhaled nitric oxide for the adult respiratory distress syndrome. N Engl J Med 1993;328:399-405.

79. Hsu CW, Lee DL, Lin SL, et al. The initial response to inhaled nitric oxide treatment for intensive care unit patients with acute respiratory distress syndrome. Respiration 2008; 75:288-95

80. Adhikari NK, Burns KE, Friedrich JO, et al. Effect of nitric oxide on oxygenation and mortality in acute lung injury: systematic review and meta-analysis. BMJ 2007; 334:779.

81. Meade MO, Jacka MJ, Cook DJ, et al. Survey of interventions for the prevention and treatment of acute respiratory distress syndrome. Crit Care Med 2004:32:946-54

82. Afshari A, Brok J, Moller AM, et al. Inhaled nitric oxide for acute respiratory distress syndrome (ARDS) and acute lung injury in children and adults. Cochrane Database Syst Rev 2010:(7):CD002787.

83. Siobal M. Aerosolized prostacyclins. Respir Care 2004;49:640-52.

84. Walmrath D, Schneider T, Schermuly R, et al. Direct comparison of inhaled nitric oxide and aerosolized prostacyclin in acute respiratory distress syndrome. Am J Respir Crit Care Med 1996;153:991-6.

85. Dahlem P, van Aalderen WM, de Neef $\mathrm{M}$, et al. Randomized controlled trial of aerosolized prostacyclin therapy in children with acute lung injury. Crit Care Med 2004;32:1055-60.

86. Adhikari N, Burns KE, Meade MO. Pharmacologic therapies for adults with acute lung injury and acute respiratory distress syndrome. Cochrane Database Syst Rev 2004; (4):CD004477.

87. Peter JV, John P, Graham PL, et al. Corticosteroids in the prevention and treatment of acute respiratory distress syndrome (ARDS) in adults: meta-analysis. BMJ 2008;336:1006-9.

88. Bernard GR, Luce JM, Sprung CL, et al. High-dose corticosteroids in patients with the adult respiratory distress syndrome. N Engl J Med 1987;317:1565-70.

89. Steinberg KP, Hudson LD, Goodman RB, et al. Efficacy and safety of corticosteroids for persistent acute respiratory distress syndrome. N Engl J Med 2006;354:1671-84
90. Meduri GU, Golden E, Freire AX, et al. Methylprednisolone infusion in early severe ARDS: results of a randomized controlled trial. Chest 2007;131:954-63.

91. Lelcuk S, Huval WV, Valeri CR, et al. Inhibition of ischemia-induced thromboxane synthesis in man. J Trauma 1984;24:393-6.

92. Williams JG, Maier RV. Ketoconazole inhibits alveolar macrophage production of inflammatory mediators involved in acute lung injury ladult respiratory distress syndrome). Surgery 1992;112:270-7.

93. Yu M, Tomasa G. A double-blind, prospective, randomized trial of ketoconazole, a thromboxane synthetase inhibitor, in the prophylaxis of the adult respiratory distress syndrome. Crit Care Med 1993;21:1635-42.

94. Slotman GJ, Burchard KW, D'Arezzo A, et al. Ketoconazole prevents acute respiratory failure in critically ill surgical patients. J Trauma 1988;28:648-54.

95. Anon. Ketoconazole for early treatment of acute lung injury and acute respiratory distress syndrome: a randomized controlled trial. The ARDS Network. JAMA 2000:283:1995-2002.

96. Anon. Randomized, placebo-controlled trial of lisofylline for early treatment of acute lung injury and acute respiratory distress syndrome. The ARDS Network. Crit Care Med 2002;30:1-6.

97. Zeiher BG, Artigas A, Vincent JL, et al. Neutrophil elastase inhibition in acute lung injury: results of the STRIVE study. Crit Care Med 2004:32:1695-702.

98. Pacht ER, Timerman AP, Lykens MG, et al. Deficiency of alveolar fluid glutathione in patients with sepsis and the adult respiratory distress syndrome. Chest 1991:100:1397-403.

99. Groeneveld AB. Vascular pharmacology of acute lung injury and acute respiratory distress syndrome. Vascul Pharmacol 2002;39:247-56.

100. Sakr Y, Vincent JL, Reinhart K, et al. High tidal volume and positive fluid balance are associated with worse outcome in acute lung injury. Chest 2005:128:3098-108

101. Ware LB, Matthay MA. Alveolar fluid clearance is impaired in the majority of patients with acute lung injury and the acute respiratory distress syndrome. Am $J$ Respir Crit Care Med 2001:163:1376-83.

102. Matthay MA. Alveolar fluid clearance in patients with ARDS: does it make a difference? Chest 2002;122(6 Suppl):340S-3S

103. Perkins GD, McAuley DF, Thickett DR, et al. The beta-agonist lung injury tria (BALTI): a randomized placebo-controlled clinical trial. Am J Respir Crit Care Med 2006:173:281-7.

104. Gadek JE, DeMichele SJ, Karlstad MD, et al. Effect of enteral feeding with eicosapentaenoic acid, gamma-linolenic acid, and antioxidants in patients with acute respiratory distress syndrome. Enteral Nutrition in ARDS Study Group. Crit Care Med 1999;27:1409-20.

105. Marik PE, Zaloga GP. Immunonutrition in critically ill patients: a systematic review and analysis of the literature. Intensive Care Med 2008;34:1980-90.

106. Hamm H, Fabel H, Bartsch W. The surfactant system of the adult lung: physiology and clinical perspectives. Clin Investig 1992;70:637-57.

107. Gregory TJ, Longmore WJ, Moxley MA, et al. Surfactant chemical composition and biophysical activity in acute respiratory distress syndrome. J Clin Invest 1991;88:1976-81.

108. Gunther A, Siebert C, Schmidt R, et al. Surfactant alterations in severe pneumonia acute respiratory distress syndrome, and cardiogenic lung edema. Am J Respir Crit Care Med 1996:153:176-84.

109. Baker CS, Evans TW, Randle BJ, et al. Damage to surfactant-specific protein in acute respiratory distress syndrome. Lancet 1999;353:1232-7.

110. Davidson WJ, Dorscheid D, Spragg R, et al. Exogenous pulmonary surfactant for the treatment of adult patients with acute respiratory distress syndrome: results of a meta-analysis. Crit Care 2006;10:R41.

111. Bernhard W, Pynn CJ, Jaworski A, et al. Mass spectrometric analysis of surfactant metabolism in human volunteers using deuteriated choline. Am J Respir Crit Care Med 2004;170:54-8.

112. Matthay MA, Goolaerts A, Howard JP, et al. Mesenchymal stem cells for acute lung injury: preclinical evidence. Crit Care Med 2010;38(10 Suppl):S569-73.

\section{ANSWERS}

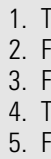

2. $\mathrm{F}$

4. $T$

$5 . F$ 